\title{
Time Series Models: Development Trends of Foodstuffs Consumption in CR Considering Healthy Eating
}

\author{
Jana Köppelová, Libuše Svatošová \\ Faculty of Economics and Management, Czech University of Life Sciences Prague, Czech Republic
}

\begin{abstract}
The agrarian sector can be understood in several ways, according to the integration of the agrarian sector into national economic structures. Understanding the agrarian sector in its complex relation to the sectors that represent the final consumption of already processed agricultural products - food (not agricultural raw materials) represents agribusiness. Among other issues, food consumption is affected by the newest nutrition trends and opinions on healthy eating and food safety. The paper's aim is an indication of development tendencies in the consumption of some selected food types and subsequent construction of a short-term forecast, considering food quality and healthy eating. Some of the prognostic procedures based on time series extrapolation have been applied in this paper. Time series analysis is therefore the starting basis for assessment of the selected foodstuffs consumption developmental tendencies and a subsequent short-term forecasts construction. The results demonstrate unambiguously that, the time series analysis methods can be applied with success in finding development tendencies of the food consumption indicators studied. Application of the adaptive models in particular, can bring good quality outcomes in this field. Anyway, it is not possible to reach an unambiguous conclusion concerning the assessment whether the consumption of some selected food types is in line with nutritional recommendations. In some cases it is, in some it is not.
\end{abstract}

\section{Keywords}

Extrapolation, time series models, forecast, agribusiness, food consumption in the CR, healthy eating, nutrition recommendations.

Köppelová, J. and Svatošová, L. (2019) “Time Series Models: Development Trends of Foodstuffs Consumption in CR Considering Healthy Eating", AGRIS on-line Papers in Economics and Informatics, Vol. 11, No. 2, pp. 43-53. ISSN 1804-1930. DOI 10.7160/aol.2019.110205.

\section{Introduction}

Another possibility of understanding the agrarian sector is the agri-food sector, which serves primarily to ensure the nutrition of the population and is part of the agribusiness. The economic stability of the agri-food sector is due to a guaranteed level of demand, but is significantly affected by emergencies such as crop failure or fear of health risks from the consumption of certain foods, as well as regulatory intervention by the EU. The agrifood sector remains one of the most stable sectors of the Czech economy. However, the sector's most pressing challenge today is the lack of permanent but also seasonal labor. The food market as a whole has been exceptionally stable, in principle it is subject to crisis or conjunctural influences only insignificantly. On the other hand, it is strongly oriented towards the end customer - the individual consumer. The foodstuffs consumption problem directly concerns everyone of us. Statisticians have followed various $\mathrm{CR}$ food consumption indicators for almost a hundred years already. Data from the food consumption field on the domestic market have been collected by the Czech Statistical Office (ČSÚ) since 1948 already, applying the Family Accounts Statistics. This way the Office has continuous time series available from this field. Without quantitative information knowledge one cannot perform decision making practically, regardless the field of interest. Quantitative information knowledge makes the increase possible of accuracy of the forecasts constructed, or the indication of changes in the nutrition trends or eating habits, too. The eating habits level is different in every country since it is affected by many factors such as, e.g., demography, habits of the population, or level of economics or farm production. Study of the differences in eating among the adults 
with differing socio-economic status (SES) and trends in time, was the object of study by Hulshof et al. (2003).

Procházková et al. (2016) have recalled an important fact concerning the reduction of arable land area which can lead to growing worries as to the food self-sufficiency secured. The low food self-sufficiency can then affect negatively both the stability of prices and food security, being often discussed recently. Restrictions on agricultural production can then have negative impacts not only from the consumers viewpoint (higher prices of imported foodstuffs, worse quality etc.), but from the ecological and environmental aspects, too, and all in all, they affect negatively the development of the countryside. And in the case of livestock production in particular, the food self-sufficiency lags behind the needs in the Czech Republic. The total farm production value in 2017 made it about 133 billion CZK, out of which the livestock production was about 51.4 billion CZK and the crop production then about 73.7 billion $\mathrm{CZK}$. Meat consumption in the CR is around $80 \mathrm{~kg}$ per person in the long run. The most popular meat in the CR is pork meat which is consumed by an average Czech the most. Poultry meat consumption is on increase in the long run, too, it is the second most popular meat here. However, meat production in Czechia is relatively steadily declining even despite the increasing subsidies and livestock production support. Náglová and Horáková (2016) dealt with the meat industry, too, in their work.

Food consumption is, among other things, one of the basic needs of a human being. Its analysis is possible from many points of view. The global food consumption, not omitting global food demand and supply, was the object of attention by Smutka et al. (2009). Kearney (2010) in his work dealt with capturing of the trends and food consumption forecast up to 2050, both all the world over and in various regions. He dealt with the principal factors mostly influencing the food consumption trends observed. Great shifts in the field of catering have recently been observed all the world over. Human health is one of the reasons of these changes at both the global and regional levels. Human health is one of the key factors facilitating the transition to ,healthy nutrition“. High level of obesity, cardiovascular diseases and cancer belong among the most frequent aftermath of unhealthy eating. Therefore, food policies of the future have to take the farming sector, human health and the environment into account.

The opinions concerning healthy eating and the newest trends in food consumption influence the final consumption significantly. Healthy eating currently is the object of interest of many scientific works very often. Olsen and Tuu (2017) in their work dealt with a comparison of the healthy eating value and self-indulgence. Healthy eating is very fashionable. Healthy food is aimed in particular at body weight regulation, nevertheless, a big and fast weight loss is not its purpose. The aim of healthy eating is maintenance of a stable body weight, gradual and permanent weight loss in the case of need, but mainly the elimination of health risks resulting from inappropriate modern diet and bad eating habits. The purpose is a style of life, the aim of which is vitality, stronger health and psychic serenity. It can be reached by the consumption of tasty and quality food, balanced nutrient intake, enough minerals and vitamins and optimal habits. However, healthy eating is actually practised by a fraction of the population only and still less of these actually know how the healthy eating is to look. In the today's hurried time it is unfortunately quite common to eat in the fast food. When you say „fast food“, everyone can certainly imagine a big hamburger with crips, a hot dog or oversweetened lemonades. To prepare such food improper technologies are practised, mainly frying in burned oil. This type of refreshment represents mostly an excessive supply of hidden energy in the form of sugars, animal fats, salt and cholesterol to our body, what has a very negative impact upon our health. Šrádl and Mikhalkina (2014) examined the extent of changes in consumer preferences as connected with the arrival of supranational oligopoly chains including the fast food restaurants in the $\mathrm{CR}$. The fast food refreshment became a prominent feature of children's eating in the United States in particular, and it has kept appearing still more often all the world over. The aim of the Bowman et al. (2004) study was to verify the effect of fast food refreshment upon the dietary factors connected with the obesity risk. Obesity represents a socio-economic problem. A reason of a different approach to more healthy eating may be the household's income. The efficient strategy for public health is a comprehensive political approach taking into account the behavioural nutrition and the foodstuffs choice economics (Drewnowski and Darmon, 2005). McCrory et al. (1999) in their work examined the connect- ions between meal consumption 
frequency in the restaurants and the body fat volume in the adults.

The gravity centre of this paper is laid in capturing and assessment of the basic development trends in consumption of some selected food sorts. The development trends found are put in connection with factors offering an assumption of their capacity to influence the consumption (information on the product composition or healthy nutrition views), what should lead to a more precise forecast. The expected consumption estimates of separate food types can offer an important information both from the economic and marketing viewpoints. In the field of food consumption forecasting various model procedures have been applied, of which the time series analysis techniques start being applied more often currently. The reason, in particular, are the undemanding conditions concerning input data, since there are the techniques based on time series model extrapolation and on the course of values over time only (Kába, 1997). Thanks to undemanding conditions for the input data these offer a simpler alternative for the forecasting as compared with forecasting using the econometric models, applied by Dozorova and Ulmanova (2015). The analyses done have shown that, the adaptive time series models in particular, and the application of these, can offer a comparatively good quality forecast (Svatošová and Köppelová, 2017). The adaptive time series analysis models will be applied in this study, too, in order to assess the development trends in food consumption and to perform the subsequent consumption forecasts for the close future.

It must not be forgotten that food consumption, as one part of agribusiness, is very sensitive to any negative information regarding individual food products. It is particularly sensitive to information based on negative findings of the State Control Authority and Sanitary and Veterinary Authority. The Czech market is also negatively reflected in cases of so-called double quality food across the EU.

\section{Materials and methods}

The source of data applied in the empirical analysis is the Czech Statistical Office (ČSÚ). The data have been collected in time series with annual frequency. Based on the ČSÚ survey a total of 33 annual time series concerning the basic food types consumption have been analyzed, with the 1989-2017 reference period.

The following foodstuff groups have been included in the processing:

- cereals and bakery products (6 items - cereals total, durable pastry, pasta, rice, bread, wheat bread)

- meat in terms of carcass weight (5 items - meat total, beef, pork, poultry, fish)

- milk, milk products, cheese and eggs ( 3 items - milk and milk products total, cow milk, cheeses)

- fats and oils (4 items - fats and oils total, butter, lard, edible vegetable fats and oils)

- sugar, sweets and confectionery (3 items - sugar total, confectionery, chocolate)

- non-alcoholic beverages (3 items - mineral waters, soda waters, lemonades)

- vegetables, pulses, potatoes (6 items - vegetables total, tomatoes, potatoes, lettuce, spinach, legumes)

- fruits in terms of fresh (3 items - fruits total, southern zone fruits, moderate zone fruits).

For effective implementation the SAS statistical software has been used, the Time Series Forecasting System (TSFS) specifically. The study is presuming the adaptive models application in particular, since these take aging of the data in account and usually offer a higher quality forecast. The SAS system offers a very wide scale of adaptive models, both from the exponential smoothing models group and from the Box-Jenkins methodology based models group. Applying a lot of diagnostic tests based on the study of the time series properties (Arlt and Arltová, 2009), the SAS is then in the position to design the perfectly suitable forecasting models. In quality assessment of the forecasts designed the Mean Absolute Percent Error (MAPE) measure and the relative forecast error rp have been applied, subsequently the mean relative forecast error, the two of these defined by the following relations:

$$
\begin{aligned}
& \text { M.A.P.E. }=\frac{100}{n} \sum_{t=1}^{n}\left|\frac{y_{t}-y_{t}^{\prime}}{y_{t}}\right| \\
& r p=\frac{\left|y_{t}^{\prime}-y_{t}\right|}{y_{t}} \bullet 100
\end{aligned}
$$

kde $y_{t}$ eventually y't $(\mathrm{t}=1,2, \ldots, n)$ are the real, eventually smoothed (theoretical) values of the given time series and $n$ represents the number of observations in the series. Also the testing parts of the time series studied have been applied, where the pseudoforecast was established always for three years. For every year of the estimate 
the relative error of the forecast has been obtained and subsequently the mean relative error for the whole three-year period has been calculated, in order to obtain a final assessment of the forecast quality. A research into the properties of various measures serving in assessment of the time series models quality - inclusive of the MAPE - was performed by Mahmoud and Pegels (1990).

The MAPE measure has been applied, among other authors, also by Kalekar (2004) in the study of the exponential models quality in application of these on seasonal time series, or Ganquiong et al. (2010) in their study of farm products market prices short-term forecast.

As a starting point for the assessment of development trends in connection with the correct nutrition requests, a material by the Ministry of Health, titled Health 2020 has been used, from which the specific recommendations concerning healthy eating were drawn (Společnost pro výživu, 2018).

\section{Results and discussion}

\section{Time series models constructed and assessment of these}

The TSFS model applied will automatically find the most suitable model both for description of the indicators studied development tendencies and for future development forecasting. The model quality has been assessed using the MAPE measure and for the forecast quality assessment the relative forecast error and the mean relative forecast error have been used.

The Table 1 summarizes the findings - the indicator studied and the best model chosen for it, incl. of the MAPE value obtained, representing

\begin{tabular}{|c|c|c|}
\hline Food & Model & $M A P E$ value in \% \\
\hline Cerals - total & Linear Holt Exponential Smoothing & 3.11 \\
\hline Long Pastry & Log Linear Trend & 5.07 \\
\hline Pasta & Log Linear Holt Exponential Smoothing & 6.65 \\
\hline Rice & Log Linear Trend & 5.65 \\
\hline Bread & Linear Holt Exponential Smoothing & 2.7 \\
\hline Bread of wheat & Damped Trend Exponential Smoothing & 4.01 \\
\hline Meat - total & Log Simple Exponential Smoothing & 2.17 \\
\hline Beef & Log Linear Holt Exponential Smoothing & 5.89 \\
\hline Porc & Damped Trend Exponential Smoothing & 2.18 \\
\hline Poultrymeat & Damped Trend Exponential Smoothing & 3.56 \\
\hline Fish & Linear Holt Exponential Smoothing & 6 \\
\hline Milk and milk products & Damped Trend Exponential Smoothing & 3.12 \\
\hline Cow's milk & Log Simple Exponential Smoothing & 4.6 \\
\hline Cheese & Damped Trend Exponential Smoothing & 4.36 \\
\hline Fats and oils & Log Simple Exponential Smoothing & 1.25 \\
\hline Butter & Log Simple Exponential Smoothing & 5.94 \\
\hline Lard & Log Linear Holt Exponential Smoothing & 3.14 \\
\hline Edible vegetable fats and oils & Simple Exponential Smoothing & 1.32 \\
\hline Sugar - total & Linear Holt Exponential Smoothing & 4.57 \\
\hline Sweets & Damped Trend Exponential Smoothing & 2.75 \\
\hline Chocolate & Linear Holt Exponential Smoothing & 6.1 \\
\hline Mineral water & Linear Holt Exponential Smoothing & 3.96 \\
\hline Soda water & Log Damped Trend Exponential Smoothing & 4.86 \\
\hline Lemonade & Damped Trend Exponential Smoothing & 2.13 \\
\hline Vegetable & Linear Holt Exponential Smoothing & 3.1 \\
\hline Tomatoes & Linear Holt Exponential Smoothing & 9.7 \\
\hline Potatoes & Linear Trend & 2.14 \\
\hline Lettuces & Log Damped Trend Exponential Smoothing & 16.2 \\
\hline Spinach & Damped Trend Exponential Smoothing & 17.9 \\
\hline Pulses & Damped Trend Exponential Smoothing & 4.6 \\
\hline Fruit - total & Linear Holt Exponential Smoothing & 4.41 \\
\hline Fruit of the mild belt & Log Damped Trend Exponential Smoothing & 3.7 \\
\hline Subtropical and tropical fruit & Simple Exponential Smoothing & 6.8 \\
\hline
\end{tabular}

Source: Own processing

Table 1: Overview of time series models applied with the MAPE values obtained 
the assessment criterion for the model quality assessment.

The results presented in Table 1 show that, in the position of the most suitable ones, the adaptive models are taking place actually, of these then the exponential smoothing models in the first place. Most often the Holt exponential smoothing model, the exponential smoothing model with damped linear trend and the simple exponential smoothing model took place. In several - not many - cases, the classical analytical model - linear trend model - succeded as the best one.

The mean absolute percent error (MAPE) value did not exceed $5 \%$ in most models, what supports the high quality of the models. As long as the MAPE measure value fluctuates within an interval of not more than up to $10 \%$, the given model can still be taken as one of comparatively good quality. Higher than $10 \%$ MAPE values happened in the models of spinach and lettuce consumption only.

The forecasts quality also can be valuated very positively. As an excellent one the quality of forecasts can be assessed where the relative forecast error and consequently the mean relative forecast error (3 years) did not exceed 5\%.

Such low values of the measures mentioned have been achieved in $66.7 \%$ cases of the indicators studied from the food consumption field. In $27 \%$ indicators the relative, or the mean relative forecast error value has been recorded within $5 \%-10 \%$. The forecasts obtained at such a level can be classified as very good. The results obtained are proving that, the food consumption forecasts for the one closest future period - coming out from the time series models constructed - can be taken as very probable ones.

The Table 2 is presenting the actual consumption

\begin{tabular}{|c|c|c|c|c|}
\hline Food & Consumption in 1989 & Consumption in 2017 & Forecast for 2018 & Relative error of forecast in $\%$ \\
\hline Cerals - total & 156 & 143.5 & 141.0 & 1.59 \\
\hline Long Pastry & 6.5 & 7.8 & 10.1 & 8.70 \\
\hline Rice & 3.96 & 6.5 & 5.7 & 8.35 \\
\hline Bread & 56.8 & 39.2 & 37.2 & 2.80 \\
\hline Meat - total & 97 & 80.3 & 79.3 & 2.63 \\
\hline Beef & 30 & 8.4 & 7.0 & 6.74 \\
\hline Porc & 49.9 & 42.3 & 41.0 & 3.06 \\
\hline Poultrymeat & 13 & 27.3 & 27.7 & 4.25 \\
\hline Fish & 6 & 5.4 & 5.8 & 0.19 \\
\hline Cheese & 7.8 & 13.2 & 13.2 & 3.11 \\
\hline Fats and oils & 28.8 & 27.1 & 27.0 & 0.74 \\
\hline Butter & 9.4 & 5.0 & 5.5 & 3.73 \\
\hline Lard & 6.8 & 4.0 & 4.2 & 1.48 \\
\hline Edible vegetable fats and oils & 12.5 & 17.6 & 17.2 & 1.76 \\
\hline Sugar - total & 39.8 & 34.9 & 32.6 & 4.55 \\
\hline Sweets & 5.1 & 7.1 & 7.1 & 1.93 \\
\hline Chocolate & 0.9 & 2.7 & 2.8 & 5.03 \\
\hline Mineral water & 14.1 & 55.3 & 60.6 & 4.85 \\
\hline Spinach & 0.1 & 1.2 & 1.3 & 14.60 \\
\hline Pulses & 1.3 & 2.9 & 3.2 & 7.90 \\
\hline Fruit - total & 70.5 & 82.0 & 83.9 & 2.11 \\
\hline Fruit of the mild belt & 53.6 & 46.9 & 48.1 & 5.16 \\
\hline Subtropical and tropical fruit & 16.9 & 35.1 & 33.5 & 2.28 \\
\hline
\end{tabular}

Source: Own processing

Table 2: The constructed forecasts for 2018 incl. of relative forecast error values. 
in the first and last periods studied (meaning the 1989 and 2017 years), the forecasts constructed using the time series models for 2018 and the relative forecast error for the assessment of the forecast given.

The consumption development of separate food sorts is going to be confronted subsequently with healthy eating requirements.

\section{Development tendencies in the consumption of selected food types}

This chapter is dealing with a description of the past development of selected food types since 1989 until 2017. Among the selected food types taken in account here belong cereals, meat, milk and milk products, oils and fats, sugars, fruit and vegetables. Graphical presentation has been employed here, too. Anyway, due to holding to the required study extent, only some selected indicators' development has been presented graphically.

\subsection{Cereals}

Cereals consumption in total recorded a more pronounced decline over the 1969-1999 years. Since 2000 the consumption of cereals has been maintained - with alternating fluctuations - about $140 \mathrm{~kg}$ per person per year. The forecast for the next year constructed using the Holt exponential smoothing model is assuming a consumption of $142 \mathrm{~kg}$ per person/year. The Figure 1 is showing the consumption development of selected types of cereals (bread, wheat pastry, pasta and rice) over 1989-2017. Concerning the flour products, from the healthy eating point of view it is recommended to consume whole wheat flour products instead of white flour products and to prefer at the same time pasta and rice in the menu, due to the low glycemic index of these. The consumption increase of pasta and rice is evident as shown in the Figure 1, which is in line with the healthy eating recommendations. Rice consumption is growing on average by $2 \%$ annually, pasta then by $3.4 \%$. As far as pastry is concerned, consumption increase is coming here for wheat pastry, what of course is not in line with healthy eating. Considering the usual weight of one slice of bread and one bread roll or roll at $43 \mathrm{~g}$, then the daily consumption takes it 3 bread rolls and 2.4 slices of bread.

Rice consumption, showing an increasing trend in the $\mathrm{CR}$ and recording a moderate increase worldwide, too (Kearney, 2010), is recommended, in particular from the cereals. Consumption of wheat worldwide has recorded a more significant growth, what has been supported by its increase of consumption in the CR, too, but this does not quite correspond to healthy nutrition.

\subsection{Meat}

Consumption of meat in total recorded a significant decrease between the 1989 to 1993 years. By $16.2 \mathrm{~kg}$ per person/year actually. Over the recent years it has been fluctuating always about $80 \mathrm{~kg}$ per person/year what has been supposed, too, for use in the simple exponential smoothing model chosen as the most suitable one for the analysis and forecasting of future development of the given indicator.

Consumption development trends of the separate meat types differ mutually. As Figure 2 shows it, the consumption of meat and meat products also does not match too much with the nutrition recommendations. Concerning healthy nutrition, the recommendations offer fish and fish products consumption, rich in the omega-3 fatty acids and conversely, meat and meat products consumption with high contents of fat should be limited (pork and sausages in particular). However,

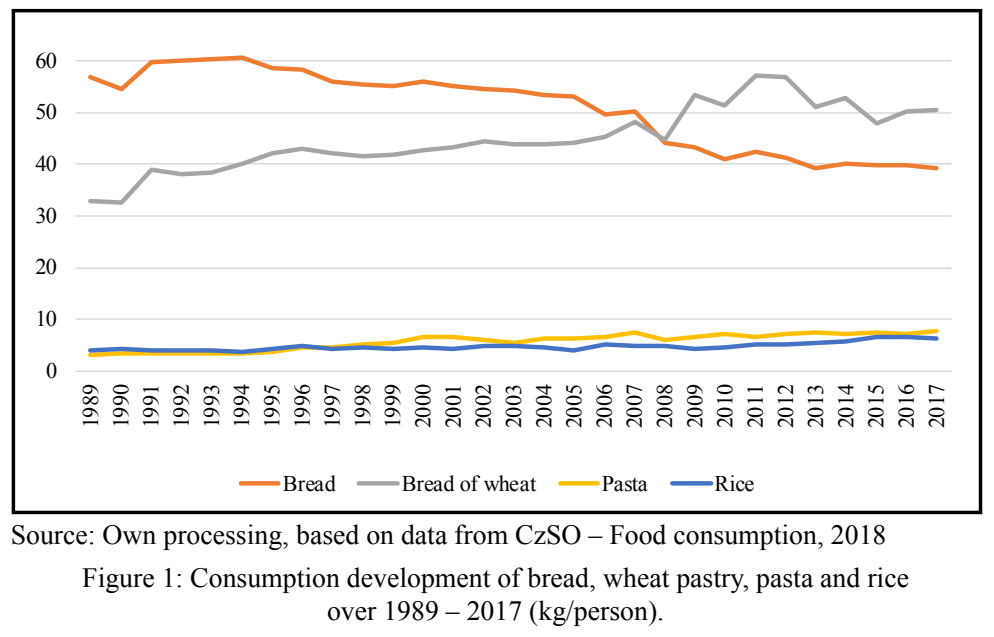




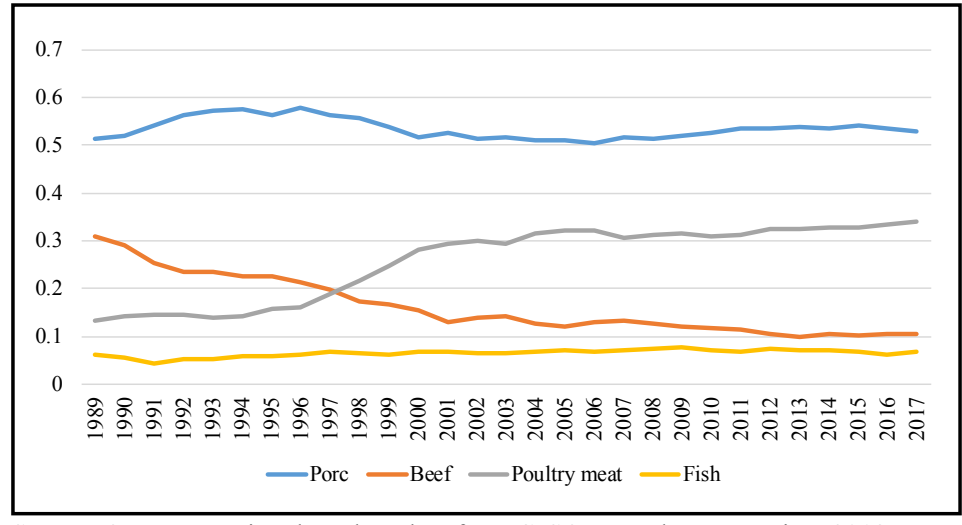

Source: Own processing, based on data from CzSO - Food consumption, 2018

Figure 2: Consumption development of separate types of meat over 1989 - 2017 (kg/person)

a slight decrease only has been recorded in pork consumption over the studied period. A more pronounced decrease has been recorded in beef and conversely, in poultry meat consumption a practically permanent growth has been monitored. Both of these trends have probably been affected by prices. It concerns both the beef consumption decrease and the poultry meat consumption growth when not even during the period of the bird flu occur-ence any consumption drop was recorded, thanks to a very low price of poultry meat. All in all, despite the nutrition recommendations, there was no change in the fish and fish products consumption.

As it concerns meat and meat products - despite the fact that meat is an important component of human diet and it is a part of most dishes in the developed countries, in many developing countries there are still the dominant sources of proteins from other than animal origin. A prominent increase of meat consumption in total is appearing worldwide, in Asia in particular. But the consumption of beef is stagnating worldwide, while in some regions - in the developing countries in particular - it has slightly increased, in others (North America, Europe) it has slightly decreased. Great Britain has had the lowest red meat consumption in Europe. In the $\mathrm{CR}$ has the beef consumption over several recent years remained at an approximately stable level. Conversely, an increase of poultry meat consumption has been recorded worldwide (Kearney, 2010), what corresponds to the outcomes of this work.

\subsection{Milk and milk products}

For the description of milk and milk products in total consumption development tendencies the exponential smoothing model with damped linear trend has been chosen as the most suitable one. The forecast constructed using it is presenting a slight increase taking in account the $240 \mathrm{~kg}$ per person/year consumption of milk and milk products over the 2011 to 2018 years. Since the beginning of the period observed, i.e. since 1989 up to 1997, a sharper decline happened (by $65 \mathrm{~kg}$ per person/year), an increasing trend was recorded within the 1998 - 2010 period on the contrary, up to $249 \mathrm{~kg}$ per person/year. From the healthy nutrition viewpoint it is recommended to include milk and milk products in the diet daily. The Figure 3 shows again, regretfully, the current milk and milk products consumption not to be much in line with the recommendations mentioned. Cow milk consumption is showing a declining trend over the period up to 2005. Since 2005 until 2007 the consumption maintained a level approximately $60 \mathrm{~kg}$ per person/year, what means $0.16 \mathrm{~kg}$ daily. But the cheese consumption in total over the period was growing and currently it represents a daily consumption of $0.036 \mathrm{~kg}$ per person. As curd is concerned, its consumption recorded the most significant drop in 1991. Since then it has slowly grown up to the value of $4.7 \mathrm{~kg}$ per person/year, which is the consumption much close to the same at the very beginning of the period studied.

Variable consumption trends have been recorded worldwide by the livestock origin products such as milk, butter and cheese, incl. of eggs and milk products; a slight increase in Europe recently, in the Eastern Europe in particular, and a slight decrease in North America on the contrary, and a sharper decrease in Oceania (Kearney, 2010).

\subsection{Oils and fats}

Oils and fats consumption in total has recorded the greatest changes over the period under study (Figure 4). At the beginning of the period 


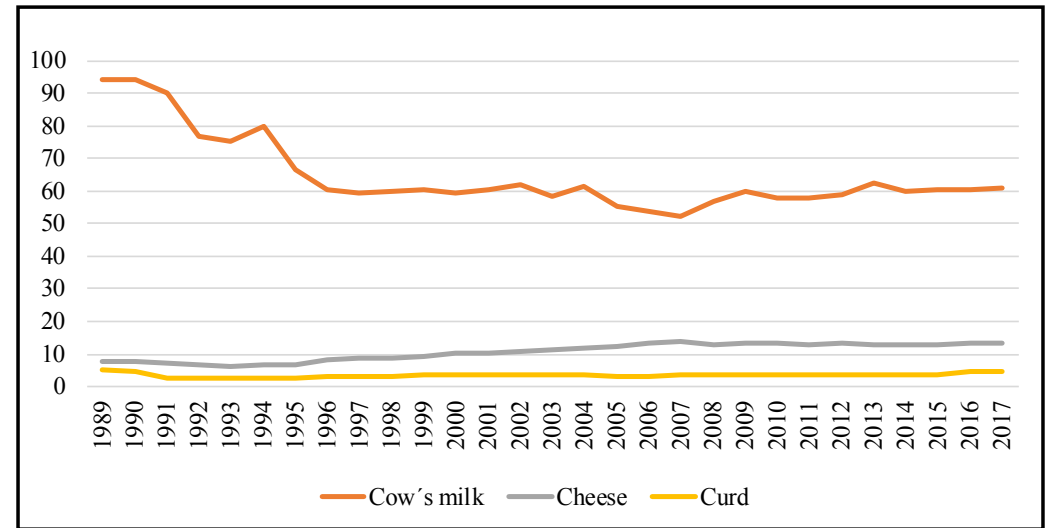

Source: Own processing, based on data from CzSO - Food consumption, 2018

Figure 3: Consumption development of cow milk, cheese and curd over $1989-2017$ ( $\mathrm{kg} / \mathrm{person})$.

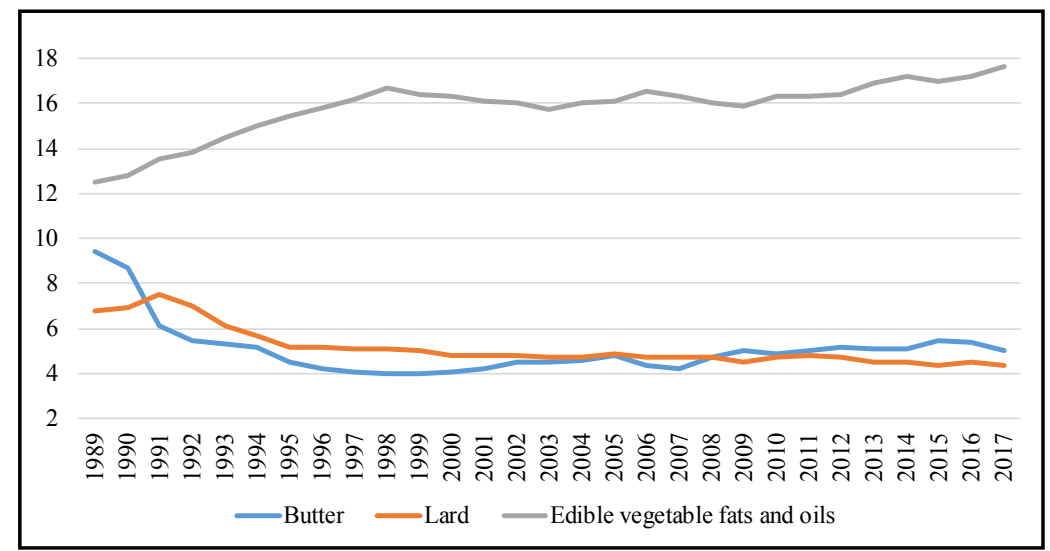

Source: Own processing, based on data from CzSO - Food consumption, 2018

Figure 4: Consumption development of butter, lard and edible vegetable fats and oils ( $\mathrm{kg} /$ person)

- from 1989 till 1996 - the consumption was decreasing. Since this section it maintained a level of $25.5 \mathrm{~kg}$ per person/year up to 2009, when an increase appeared again. A slight increase of consumption is also assumed by the simple exponential smoothing model, chosen as the most suitable for the indicator studied analysis. The recommendations concerning healthy nutrition are based in the growth of vegetable oils intake and reduction of animal fats. Consumption of edible vegetable oils hence is in line with nutrition trends since the consumption has shown a long-term tendency of growth.

On the other hand, consumption of lard has recorded a permanent slight decrease. Worldwide trends have recorded a significant decrease in the animal fats consumption together with the growth of vegetable oil consumption (Kearney, 2010).

\subsection{Sugars}

One of the most basic and most emphatic recommendations concerning healthy nutrition is reduction of the consumption of sugars (in total). The recommended sugar consumption is about $60 \mathrm{~g}$ per person/day. It corresponds to an annual consumption of $22 \mathrm{~kg}$ per person, i.e. $63 \%$ of the actual consumption $34.9 \mathrm{~kg}$ per person/year in the year 2017. The model chosen for the analysis of the given indicator development - the Holt exponential smoothing model - is assuming sugar consumption at $32.6 \mathrm{~kg}$ per person/year in 2018, what means a slight drop as compared with the previous year 2017. During the period under study is a decrease recorded in total, from a long-term viewpoint (with varying fluctuations), but a very slight decrease only.

\subsection{Drinks}

Out of the alcoholic drinks beer ,is enjoying“ the highest consumption, its consumption is comparatively high, 146.91 per person/year. However, over the past 12 years a decrease of this consumption has been observed, on average by $0.8 \%$ annually, and an increase of wine consumption has appeared on the other hand, 
by $1.5 \%$ on average annually. The healthy nutrition tolerates a daily consumption up to $20 \mathrm{~g}$ of alcohol, which means 0.21 of wine or 0.51 beer, hence, considering that only the adults consume alcohol, this limit has been severely violated.

When a more detailed look at the drinks consumption is taken, it is apparent that, in the consumption of non-alcoholic drinks sweet lemonades consumption prevails, in spite of the decrease over the recent years. A forecast for the 2018 year, constructed using the best model chosen - the exponential smoothing model with damped linear trend - is awaiting a further decrease, from 89.3 1 per person/year in 2017, down to 85.21 per person/year. In 2017 it fell below the 90 litres per person/year limit, what was close to the consumption in 2002. The lowest consumption has been recorded concerning soda water, reaching less than 40 litres per person/year in 2011.

\subsection{Fruit and vegetables}

Fruit consumption has been even exceeded considering the healthy nutrition recommendations. The standard requires $60.2 \mathrm{~kg}$ per person/year consumption. The total consumption reached $82 \mathrm{~kg}$ per person/year value in 2017. The Holt exponential smoothing model having been constructed as the best one, has presumed a further increase of fruit consumption - actually $83.9 \mathrm{~kg}$ per person/year in 2018.

Consumption of vegetables, too, has recorded an increasing tendency (by $25 \%$ ) over all the period under study (Figure 5). However, when compared with the consumption recommended regarding healthy nutrition, the consumption of vegetables still is not sufficient. Regarding the healthy nutrition every one should consume about $350 \mathrm{~g}$ daily, which makes it the annual consumption of $128 \mathrm{~kg}$ per person/year, but in 2017 the consumption of vegetables made it $88.2 \mathrm{~kg}$ per person/year only. The forecast for 2018, based on the Holt exponential smoothing model, is still presuming a drop down to $86.4 \mathrm{~kg}$ per person/year value, regretfully.

As it concerns the fruit and vegetables intake, the combined intake of these worldwide markedly exceeds the levels recommended, by $500 \mathrm{~g}$ daily at least. Even this is from the healthy nutrition viewpoint still insufficient. While fruit and vegetables production has grown over the recent years, the insufficient consumption is remaining a problem worldwide. In order to increase the consumption level, it is needed to aim at the aspects of the market-supplier chains. This will help to make fruit and vegetables accessible to poor households, too, same as to ensure the access to markets to small producers (Kearney, 2010).

\section{Conclusion}

Time series of the economic indicators frequently follow a very irregular course. Forecasting of their future development can be rather complicated in such cases. But the results of empirical analyses done have proved that, the adaptive time series models can be applied for the future food consumption forecasts with success. Hence it is possible to recommend these as an alternative or supplement to the complicated econometric models. First the quality of models constructed has been assessed in this study, using the MAPE measure, but of course the quality of forecasts, too, using the relative error of the forecast. Good quality results have been reached in both cases. The MAPE criterion value has not exceeded

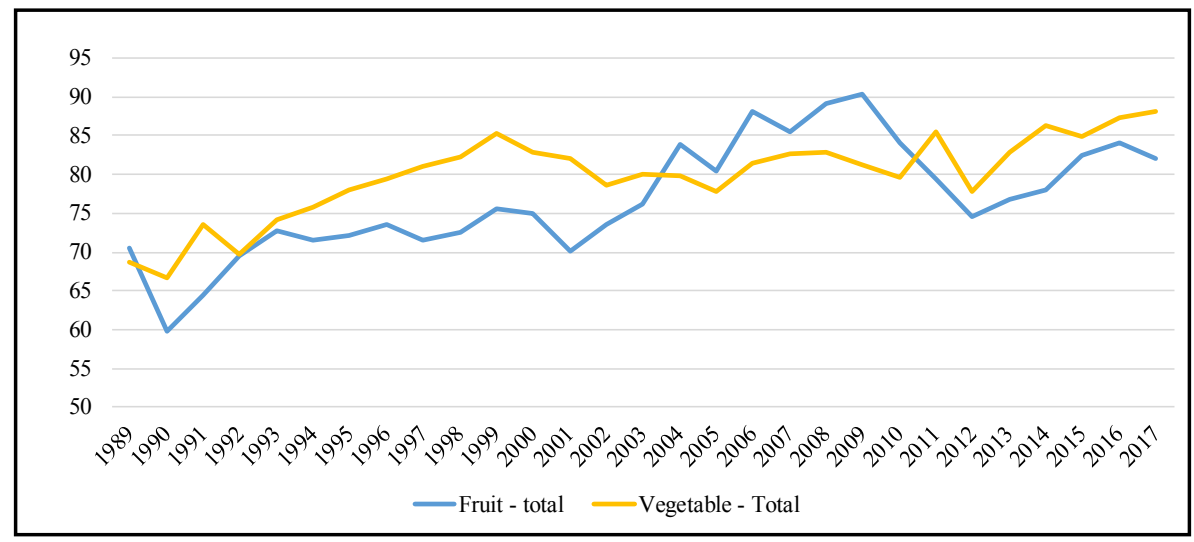

Source: Own processing, based on data from CzSO - Food consumption, 2018

Figure 5: Consumption development of fruit and vegetables in total over 1989 - 2017 (litres per person/year). 
$5 \%$ in most cases, actually in $67 \%$ cases of all the indicators. Exactly the same frequ- ency has been reached in the relative forecast error values lower than $5 \%$, which supports the high quality of the forecasts constructed.

But an assessment whether the food consumption development, inclusive of the forecast statements, correspond to the healthy nutrition principles recommended, is not so unambiguous in any case. For example, as to meat consumption, it is recommended to consume more fish, but the consumption of fish does not increase even in spite of all the recommendations. Even concerning cereals, in some cases consumption is not in line with nutrition recommendations - consumption of both wheat pastry and durable pastry increases. On the contrary, consumption of rice and pasta is consistent with the recommendations - it has an increasing tendency. Also milk and milk products consumption is corresponding to the healthy nutrition principles. Fruit and vegetables consumption is recording a growing tendency, but in case of vegetables the consumption still is not sufficient. Sugar consumption in total has a slightly declining tendency, what can be taken as a positive development, but we have to omit sugar contents in the non-alcoholic drinks; very high consumption of sweet lemonades has been recorded as compared with the mineral or soda waters.

Healthy nutrition recommendations have been taken into account to a degree, but in a comparatively large consumers group still the established traditional ways of eating predominate and moreover, food prices can influence the decisions concerning eating.

Demand for food, in 2018, focused on higherquality products in connection with the growth of the final consumer's purchasing power. This is evidenced by regular analyzes carried out in the agrarian sector. However, wage growth in the Czech economy is expected to slow in the coming years, and so this trend may not be expected to continue. There is also a noticeable shift in demand and in consumption towards Czech products (national quality mark KLASA and domestic food products labeled Czech Foodstuff or Regional Foodstuff).

\section{Corresponding authors}

Ing. Jana Köppelová

Department of Statistics, Faculty of Economics and Management, Czech University of Life Sciences Prague, Kamýcká 129, Prague, 16500 Czech Republic

E-mail: koppelova@pef.czu.cz

\section{References}

[1] Arlt, J. and Arltová, M. (2009) "Ekonomické časové řady" (Economic time series), Prague, Professional Publishing. ISBN 978-80-86946-85-6. (In Czech).

[2] Bowman, S. A., Gortmaker, S. L., Ebbeling, C. B., Pereira, M. A. and Ludwig, D. S. (2004) "Effects of fast-food consumption on energy intake and diet quality among children in a national household survey", Pediatrics, Vol. 113, No. 1., pp. 112-118. ISSN 0022-3476. DOI 10.1542/peds.113.1.112.

[3] Dozorova, T. A. and Utmanova, N. A. (2015) "Econometric methods in forecasting food consumption", In Global Science and Innovation: materials of the VI International Scientific Conference, Vol. 1, Chicago, November 18-19 $9^{\text {th }}$ (Vol. 2015).

[4] Drewnowski, A. and Darmon, N. (2005) "Food choices and diet costs: an economic analysis", The Journal of Nutrition, Vol. 135, No. 4, pp. 900-904. E-ISSN 1541-6100, ISSN 0022-3166. DOI 10.1093/jn/135.4.900.

[5] Ganqiong, L., Shiwei, X., Zhemin, L. and Xiao-xia, D. O. N. G. (2010) "Study on Super Shortterm Forecasting for Market Price of Agro-products - Based on Modern Times Series Modeling of Daily Wholesale Price of Tomatoes", Journal of Huazhong Agricultural University (Social Sciences Edition), Vol. 6. ISSN 1008-3456.

[6] Hindls, R., Hronová, S. and Novák, I. (2000) "Metody statistické analýzy pro ekonomy" (Methods of statistical analysis for ecnomists), Prague. ISBN 80-7261-013-9. (In Czech). 
[7] Hulshof, K. F. A. M., Brussaard, J. H., Kruizinga, A. G., Telman, J. and Löwik, M. R. H., (2003) "Socio-economic status, dietary intake and $10 \mathrm{y}$ trends: the Dutch National Food Consumption Survey", European Journal Of Clinical Nutrition, Vol. 57, No. 1. E-ISSN 1476-5640, ISSN 0954-3007. DOI 10.1038/sj.ejcn.1601503.

[8] Kalekar, P. S. (2004) "Time series forecasting using holt-winters exponential smoothing", Kanwal Rekhi School of Information Technology, pp. 1-13.

[9] Kearney, J. (2010) "Food consumption trends and drivers", Philosophical Transactions of The Royal Society B: Biological Sciences, Vol. 365, No. 1554, pp. 2793-2807. DOI 10.1098/rstb.2010.0149.

[10] Kába, B. (1997) "Konstrukce kombinovaných předpovědí časových řad ekonomických ukazatelů", Constructions of combined forecasts of time series of economic indicators), Zborník vedeckých prác z MVD, Nitra (In Czech).

[11] Mahmoud, E. and Pegels, C. C. (1990) "An approach for selecting times series forecasting models", International Journal of Operations \& Production Management, Vol. 10, No. 3, pp. 50-60. ISSN 0144-3577. DOI 10.1108/01443579010003003.

[12] McCrory, M. A., Fuss, P. J., Hays, N. P., Vinken, A. G., Greenberg, A. S. and Roberts, S. B. (1999) "Overeating in America: association between restaurant food consumption and body fatness in healthy adult men and women ages 19 to 80, Obesity Research, Vol. 7, No. 6, pp. 564-571. ISSN 1071-7323.

[13] Náglová, Z. and Horáková, T. (2016) "Influence of Qualitative Factors on Quantitative Determinants in the Czech Meat Industry Economy“, AGRIS On-line Papers in Economics and Informatics, Vol. 8, No. 4, pp. 111-123. ISSN 1804-1930. DOI 10.7160/aol.2016.080410.

[14] Olsen, S. O. and Tuu, H. H. (2017) "Time perspectives and convenience food consumption among teenagers in Vietnam: The dual role of hedonic and healthy eating values", Food Research International, Vol. 99, Part 1, pp. 98-105. ISSN 0963-9969. DOI 10.1016/j.foodres.2017.05.008.

[15] Procházková, R., Prášilová, M. and Hloušková, Z. (2016) "Efficiency of agriculture as related to foodstuffs Autarky in the Czech Republic", Proceedings of International conference Agrarian Perspectives $X X V$, Prague, pp. 284 - 290. ISBN 978-80-213-2670-5.

[16] Smutka, L., Steininger, M. and Miffek, O. (2009) "World agricultural production and consumption“, AGRIS on-line Papers in Economics and Informatics, Vol. 1, No. 2, pp. 3-12. ISSN 1804-1930.

[17] Společnost pro výživu [Online]. Available: http://www.vyzivaspol.cz/vyzivova-doporuceni-proobyvatelstvo-ceske-republiky. [Accessed: 12 April 2018] (In Czech)

[18] Svatošová, L. and Köppelová, J. (2017) "The Use of Combined Models in the Construction of Foodstuffs Consumption Forecasting in the Czech Republic", AGRIS On-line Papers in Economics and Informatics, Vol. 9, No. 4., pp. 81-89. ISSN 1804-1930.

[19] Šrádl, K. and Mikhalkina, E. (2014) "Competition among Companies in the Fast Food Market in the Czech Republic", AGRIS On-Line Papers in Economics and Informatics, Vol. 6, No. 4. ISSN 1804-1930. 